\title{
Characterization \& Batch Sorption Study for Chromium (VI) Removal from Aqueous Solutions by Activated Carbon Adsorbent Prepared from Indigenous Sugarcane Bagasse
}

\author{
Zulfiqar Ali Solangi ${ }^{1}$, Zulfiqar Ali Bhatti ${ }^{1}$, Kashif Hussain Mangi ${ }^{2,3}$, Khadija Qureshi $^{1,}{ }^{*}$, Hira Lal Soni ${ }^{2}$ \\ ${ }^{1}$ Department of Chemical Engineering, MUET, Jamshoro, Pakistan \\ ${ }^{2}$ Department of Chemical Engineering, QUEST, Nawabshah, Pakistan \\ ${ }^{3}$ GEPEA Laboratory, University of Nantes, France \\ ${ }^{*}$ Corresponding author: khadija.qureshi@faculty.muet.edu.pk
}

\begin{abstract}
Chromium being a carcinogenic element present in drinking water in the less developed areas in the poor countries contributes to many infectious diseases. The removal of chromium traces from water needs to have an easy and efficient way for poor countries. Concerning this, a low-cost industrial bio-adsorbent based on bagasse (the sugar industry waste) is prepared and characterized for $\mathrm{Cr}(\mathrm{VI})$ removal from aqueous solutions. Preparation of the absorbent is performed by carbonization and steam activation of sugarcane bagasse (SCB). The FTIR spectra and the morphology of the adsorbent before and after $\mathrm{Cr}(\mathrm{VI})$ removal was studied using FTIR and SEM. All the experiments were carried out in a batch process with laboratory-prepared samples to study the effects of $\mathrm{pH}$, adsorbent dose, adsorbate concentration, shaking time and shaking speed. It was observed that the highest removal efficiency was achieved at $\mathrm{pH}=2$, adsorbent dose $=0.75 \mathrm{~g}$, adsorbate concentration $=60 \mathrm{mg} / \mathrm{L}$, shaking speed $=150$ $\mathrm{rpm}$, and shaking time $=20$ minutes. These results suggest that this bio-adsorbent can provide a simple, effective, and cheap method for removing $\mathrm{Cr}(\mathrm{VI})$ ions from effluents and water resources.
\end{abstract}

Keywords-Aqueous solution, sugarcane bagasse, activated carbon, sorption

\section{Introduction}

$\mathrm{T}$ HE quality of water is largely affected by the effluent from industries containing toxic heavy metals. Cr is one of the heavy metals that occur in two forms, i.e., trivalent and hexavalent [1]. The compounds of chromium are widely used in magnetic tapes, finishing of metals, electroplating, wood protection, pigments, tanning of leather, manufacturing of chemicals, electrical-electronic equipment, textile dyes, antirust agents in water cooling, and catalysis etc. [1-3]. The effects of $\mathrm{Cr}$ (VI) are very harmful including the disorder of liver, skin, kidney, respiratory organ, bronchitis, perforation of nasal septum and ulcer formation[4-6].

Growing public concern about the risks associated with $\mathrm{Cr}$ (VI) contaminated water has led to strict international regulations. US Environmental Protec-

ISSN: 2523-0379 (Online), ISSN: 1605-8607 (Print)

DOI: 10.52584/QRJ.1802.12

This is an open access article published by Quaid-e-Awam University of Engineering Science \& Technology, Nawabshah, Pakistan under CC BY 4.0 International License. tion Agency and World Health Organization (WHO) recommended $\mathrm{Cr}$ concentration in drinking water below $50 \mu \mathrm{g} / \mathrm{L}$. Pakistan has also adopted the same guidelines. In Pakistan, the industries such as leather tanning, metal finishing, chrome plating, textile, fabrication, cement, dye, and pigment generate abundant quantities of effluent with high $\mathrm{Cr}$ concentrations from 0.5 to $270 \mathrm{mg} / \mathrm{L}$ [3][7]. Therefore, it is essential that before discharge, these industries decrease $\mathrm{Cr}$ (VI) contents up to the level of acceptance. However, high costs of operating wastewater treatment systems along with the financial constraints make it one of the major problems, especially in developing countries. The traditional methods used for heavy metals removal from water and wastewater include oxidation, precipitation, electrolytic removal, membrane filtration, flotation, solvent extraction, bio reduction, ion exchange and sorption [4][8-10]. The financial problems faced by the industry needs to be investigated to find a cheap and environmentally friendly method. Sorption methods are cost-effective and safe to use. Activated Carbon 
(AC) possesses certain properties that make it adsorptive in nature. The material and the method of activation for AC preparation determine the surface functional groups. The pore structure can also be refined by the activation process. The large surface area up to $2000 \mathrm{~m}^{2} / \mathrm{g}$ is provided by micropore, mesopore and ultra-micropore [1]. An unreasonable cost of AC limits its commercial use in developing countries. There are certain benefits of the biosorption such as the possibility of metal recovery, low-cost, minimum chemical or biological regeneration of sludge, high efficiency, etc. [11][12].

Waste materials like a grape waste, rice husk, fungal biomass, distillery sludge green algae, maple sawdust, hazelnut shell, algal bloom residue derived activated carbon, wood, rice straw-based carbon, coconut tree sawdust, almond nutshell and tea leaf waste have been studied for $\mathrm{Cr}$ (VI) removal[1][4][9], [1318]. There are various functional groups attached to these materials. Some of these functional groups are aldehyde, aliphatic, alkene, hydroxyl, amide, aromatic nitro, silicate, sulphonate etc. [19][2]. FTIR studies indicated that the above functional groups are responsible for Cr (VI) sorption[6][20]. Since different materials identified in earlier studies are not easily available in Pakistan, therefore, the purpose of this study is to identify a readily available low-cost natural resources that could be used as bio-sorbent, especially for $\mathrm{Cr}(\mathrm{VI})$ removal from aqueous solutions.

In our local context, we selected SCB which is widely available in Pakistan. Pakistan produces about 16.6 million tons of SCB annually, which is used as fuel for boilers, and as raw material for the manufacture of pulp paper and boards [21]. Earlier, Gomes et. al. [15] carried out a study on chromium removal from aqueous solutions using SCB and rice husk. They conducted the batch sorption experiments to investigate the effect of different parameters, i.e., $\mathrm{pH}$, adsorbent dose, and contact time.

Cronje et. al. [3] also carried out a study on the optimization of $\mathrm{Cr}$ (VI) removal employing developing AC from SCB. The SCB used in the study was treated with zinc chloride. Similarly, there are various other studies available in the literature, but these studies are limited as far as the optimization of the removal efficiency by variation in certain parameters are concerned. In the present study activated SCB prepared by carbonization and steam activation (SCB) was used for $\mathrm{Cr}$ (VI) removal from aqueous solutions. The $\mathrm{Cr}$ (VI) ion sorption experiments were conducted at batch scale, and in the influence of different parameters was investigated. Characterization and detailed morphological study were also carried out

\section{Material \& Methods}

The following sections describe the material and methods used in this study.

\subsection{Activated Granular Activated Carbon}

Sugar Cane Bagasse (SCB) was collected from Matiari Sugar Mill Limited in Matiari district, which is located about $30 \mathrm{~km}$ from the study area of Mehran UET, Jamshoro, Sindh, Pakistan. This waste was utilized for activated carbon (AC) preparation to investigate Cr (VI) removal. Initially, SCB was ground and sieved up to the range of size from 4.0-1.7 mm. Bagasse was mixed with sugarcane molasses in a $1: 0.5 \mathrm{w} / \mathrm{v}$ ratio. The homogenized sample was compressed using Simplimet Mounting Press (model 20-1320) at a pressure of 5000 psi to form pellets of $2.5 \mathrm{~cm}$ diameter. The pellets were placed in a tubular reactor and pyrolyzed in Nitrogen (N2) atmosphere at $700^{\circ} \mathrm{C}$ for 1 hour. The sample was then cooled overnight in the furnace under an inert atmosphere. Later, the sample was activated with carbon and carbonized for $45 \mathrm{~min}$ at $850^{\circ} \mathrm{C}$ in $\mathrm{N} 2$ atmosphere. The carbonized carbon was washed using $0.1 \mathrm{~N} \mathrm{HCl}$ to remove ash and other adhering material. Carbon was washed dried and stored. Figure 1 shows the process of preparing pellets from the industrial sugar cane bagasse.

\subsection{Standard Solution Preparation}

$\mathrm{Cr}$ (VI) stock solution (1000 mg/L) was prepared by dissolving potassium dichromate $(\mathrm{K} 2 \mathrm{Cr} 2 \mathrm{O} 7)$ in one litre of deionized water. To obtain initial $\mathrm{Cr}$ (VI) concentrations of 60 to $100 \mathrm{mg} / \mathrm{L}$, the deionized water was added to the stock solution and diluted. The solution $\mathrm{pH}$ was adjusted from $2-10$ using $0.5 \mathrm{~N} \mathrm{HCl}$ and $0.5 \mathrm{~N} \mathrm{NaOH}$ respectively. All analytical grade chemicals were used in this study.

\subsection{Adsorbent Characterization}

Analytical analysis of developed sorbent loaded with activated carbon was carried out through FTIR for observing sorption before and after the experiment. The spectral range was $4000-600 \mathrm{~cm}^{-1}$. The scanning electron microscope (SEM) characterization was carried out using Jeol JSM 6380 to observe the surface texture before and after activation, and after sorption. To measure porosity, the sample was placed into a Penetrometer and the Quanta-chrome Autoscan-33 Model mercury intrusion porosimeter. For the measurement of the pore volumes between the ranges from 6.0000 to $0.0062 \mu \mathrm{m}$ radius, the Penetrometer was filled with mercury and the system pressure increased gradually 


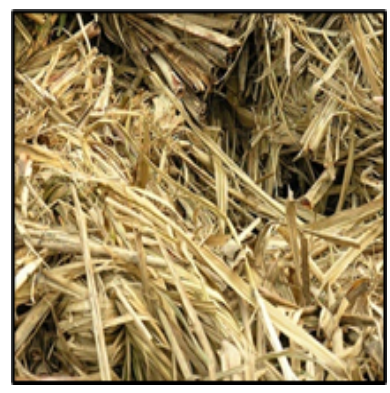

(a) Sugar cane bagasse

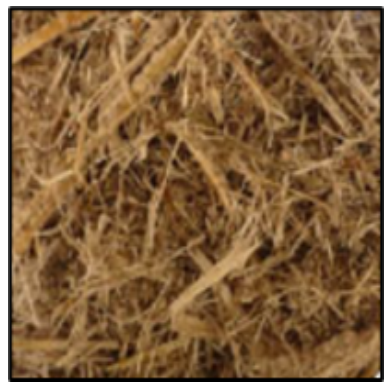

(b) Course grinding

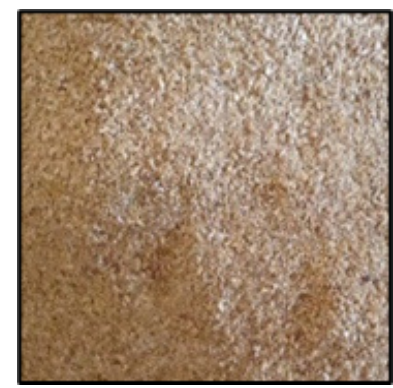

(c) Fine grinding

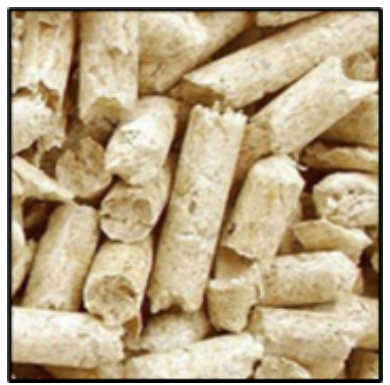

(d) Compressed pellets

Fig. 1: Process of preparing pellets from the industrial sugar cane bagasse

up to $1900 \mathrm{Kg} / \mathrm{cm}^{3}$. The calculation of the pore radius was done using the Washburn Equation [22]. For measuring the surface area, Quanta-chrome NOVA 1200 Model sorp-tometer was used. The system was heated for the removal of moisture and atmospheric gases. N2 was introduced both in liquid and gas phase, and the temperature was gradually reduced to $30^{\circ} \mathrm{C}$. The adsorption features of arsenic onto ICPG were considered under equilibrium and dynamic conditions.

\subsection{Batch Sorption Experiments}

The batch sorption experiments of $\mathrm{Cr}$ (VI) ion removal by activated SCB were carried out at ambient conditions of temperature. The solution $(100 \mathrm{ml})$ containing $60-100 \mathrm{mg} / \mathrm{l} \mathrm{Cr}$ (VI), $0.75 \mathrm{~g}$ of activated SCB was added, and $\mathrm{pH}$ was adjusted to 2 with $0.1 \mathrm{M} \mathrm{HCl-KCl}$ buffer $(5 \mathrm{ml})$. The contents were mechanically shaken at $150 \mathrm{rpm}$ for 20 minutes and filtered with filter paper (Whatman filter paper No. 42). The solution was analyzed on Variant Spectr AA 20 Plus using an airacetylene flame. Triplicate analysis $(\mathrm{n}=3)$ was carried out with integration, and delay time of 3 seconds. The removal efficiency, i.e., sorption capacity of the developed adsorbent was calculated by using Equation 1 .

$$
\text { \% Sorption }=\left(C_{0}-C_{f} / C_{0}\right) \times 100
$$

Where $C_{0}$ is the initial known concentration of metal, $C_{f}$ is remaining (final) concentration of metal ion in the solution (mg/L) [13]. At an equilibrium time, the metal uptake $\left(q_{e}\right)$ was estimated by using Equation 2,

$$
w\left(q_{e}-q_{0}\right)=v\left(C_{0}-C_{f}\right)
$$

Where qo $=0$, Eq. (2) will become:

$$
q_{e}=v\left(C_{0}-C_{f}\right) \times 100 w
$$

where $q_{e}$ represents the adsorbed amount of metal i.e. $\mathrm{Cr}(\mathrm{VI})$, and $C_{e}$ is the remaining (final) metal ion concentration $(\mathrm{mg} / \mathrm{L})$ at equilibrium time and these are

\begin{tabular}{|l|l|l|}
\hline Characteristics & Bagasse & Activated bagasse \\
\hline $\begin{array}{l}\text { Specific surface } \\
\text { area (m2/g) }\end{array}$ & 8.01 & 1537 \\
\hline $\begin{array}{l}\text { Average pore } \\
\text { diameter (nm) }\end{array}$ & 5.01 & 38.7 \\
\hline Porosity $(\%)$ & 23.22 & 64.42 \\
\hline $\begin{array}{l}\text { Total pore } \\
\text { volume }(\mathrm{ml} / \mathrm{g})\end{array}$ & 0.234 & 0.561 \\
\hline
\end{tabular}

TABLE 1: Proprtirs of prepared activated carbon

measured directly by Varian Spectr AA20 Plus at the wavelength of $357.9 \mathrm{~nm}, \mathrm{v}(\mathrm{ml})$ is the aqueous solution volume, and w is the weight $(g)$ of the adsorbent.

\section{Results \& Discussion}

This section presents the results of this study.

\subsection{Characterization of Activated Carbon}

In our study, the properties of activated carbon before and after activation were determined and the results are shown in Table 1. Analysis of results shows that the steam activation removed volatile impurities, creating a highly developed active porous surface, as well as increased the pore diameter, pore volume and specific surface area. The FTIR spectra of the adsorbents before and after $\mathrm{Cr}$ (VI) sorption indicated the number of peaks showing the functional groups. Figure 2a$2 \mathrm{~b}$ exhibits several peaks. The FTIR spectra of the adsorbent before and after $\mathrm{Cr}$ (VI) removal is shown in Figure 2a-2b. The spectra were recorded with attenuated total reflectance accessory within 4000-600 $\mathrm{cm}^{-1}$. The results of the absorption peaks with possible assignments are given in Table 2. The band frequency around $3707 \mathrm{~cm}^{-1}$ indicates the presence of hydroxyl (-OH) group and its substantial shift from 3707 to 3400 $\mathrm{cm}^{-1}$ reveals the $\mathrm{Cr}$ binding with (-OH) group. Similar assignments have been reported by Anand Kumar et. al. [19] for Bael fruit. 


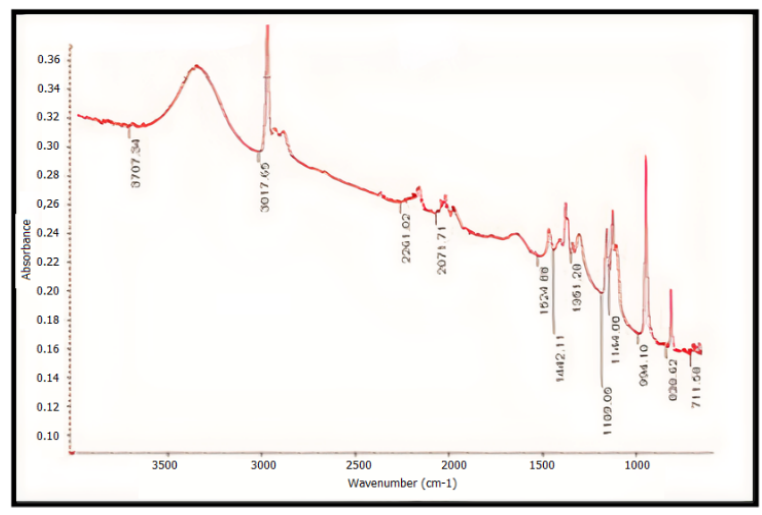

(a) Before chromium sorption

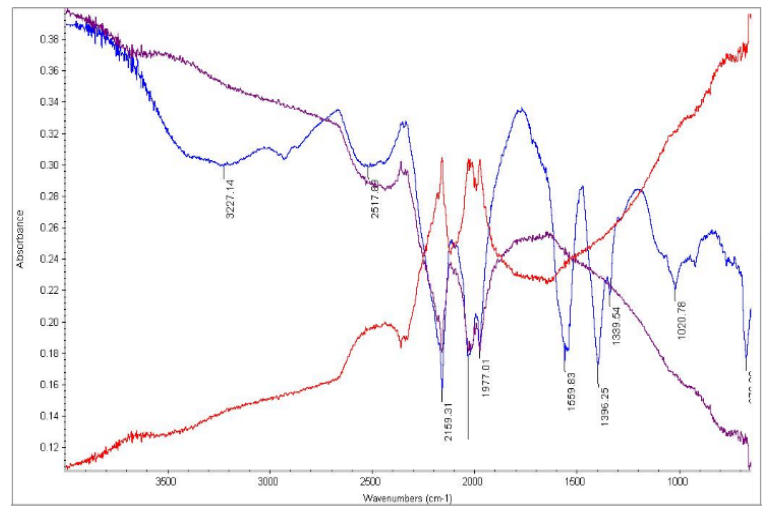

(b) After chromium sorption

Fig. 2: Fourier transform infrared (FTIR) spectrum of activated bagasse

\begin{tabular}{|c|c|c|}
\hline \multirow{2}{*}{ Adsorbent } & \multicolumn{2}{|c|}{ Activated bagasse } \\
\cline { 2 - 3 } & $\begin{array}{c}\text { before Cr } \\
\text { (VI) binding }\end{array}$ & $\begin{array}{c}\text { after Cr } \\
\text { (VI) binding }\end{array}$ \\
\hline $\mathrm{O}-\mathrm{H}$ & 3707 & 3400 \\
\hline -NH & 3210 & 3227 \\
\hline $\mathrm{C}-\mathrm{H}$ & 3017 & 2970 \\
\hline & & 2517 \\
$-\mathrm{NH} 3$ & 2261 & 2460 \\
\hline $\mathrm{C}=\mathrm{O}$ & 1525 & 1559 \\
\hline -CH3 & 1442 & 1396 \\
$-\mathrm{CH} 2$ & 1351 & 1339 \\
\hline$-\mathrm{CO}$ & - & 1020 \\
$-\mathrm{OCH} 3$ & - & - \\
\hline & 994 & \\
$\begin{array}{c}\text { Bending } \\
\text { vibrations }\end{array}$ & 838 & 650 \\
& 711 & \\
\hline
\end{tabular}

TABLE 2: FTIR spectra of adsorbent before and after Cr (VI) sorption

When activated carbon was loaded with Cr (Figure $2 \mathrm{~b})$, the N-H absorption peak shifted from 3210 to $3227 \mathrm{~cm}^{-1}$, which shows that this functional group was involved in metal binding. In $\mathrm{C}-\mathrm{H}$ stretching, the vibration was observed within $3017-2950 \mathrm{~cm}^{-1}$. Same observations have been reported for Bael fruit from 2924 to $2913 \mathrm{~cm}^{-1}$ [19]. The band 2261 and 2517 $\mathrm{cm}^{-1}$ are assigned to stretching vibrations of $-\mathrm{NH} 3$ groups. This was due to the treatment of activated carbon with hydrochloric acid. The signal observed at 1525 and $1559 \mathrm{~cm}^{-1}$ could also be assigned to $\mathrm{C}=\mathrm{O}$ vibrations. Additional peaks at 1442 and 1351 $\mathrm{cm}^{-1}$ are assigned to $\mathrm{CH} 3$ and $\mathrm{CH} 2$ which shifted to 1396 and $1339 \mathrm{~cm}^{-1}$ respectively. Additional peaks below $1000 \mathrm{~cm}^{-1}$ are due to vibrations of aromatic compounds. Here sorption may be because of physical sorption, ionic exchange, complexation with functional groups, chemical reaction with surface sites, and surface precipitations. The porosity and surface texture of the prepared activated sample was recorded by the scanning electron microscope. In Figure 3a, SEM image of SCB, prior to activation is displayed showing the absence of pores or voids. The SEM of an activated sample in Figure 3b reveals well-developed pores like capillaries open at one or both ends.

\subsection{Optimization of Developed Sorbent}

The developed sorbent loaded with activated carbon was further tested by investigating different parameters to achieve an optimized performance. Therefore, the effect of different parameters including dosage of sorbent, $\mathrm{pH}$, shaking speed and time and sorbate initial conditions were studied.

\subsubsection{Effect of $\mathrm{pH}$ on the Sorption Capacity of Acti- vated Carbon}

Solution pH is essential to study because it influences metal sorption. Chromium ions exist in the form of $\mathrm{HCrO} 4$ - at very low $\mathrm{pH}$, while at higher $\mathrm{pH}$ up to 6 , different forms such as Cr2O7-2, Cr2O4- and Cr3O102 coexist, of which $\mathrm{HCrO} 4-$ predominates. Equilibrium shifted from $\mathrm{HCrO} 4-$ to $\mathrm{CrO} 4-2$ and $\mathrm{Cr} 2 \mathrm{O} 7-2$ as the $\mathrm{pH}$ increases [9]. At lower values of $\mathrm{pH}$, due to greater attractive forces, the hydronium ions would be surrounded on the adsorbent surface, thereby increasing Cr (VI) contact with binding positions of an adsorbent. The overall surface charge on the adsorbents turned out to be negative and sorption decreased due to the rise of $\mathrm{pH}[23]$.

At increased $\mathrm{pH}(i, 5)$, there is a gradual reduction in the degree of protonation of the surface which 


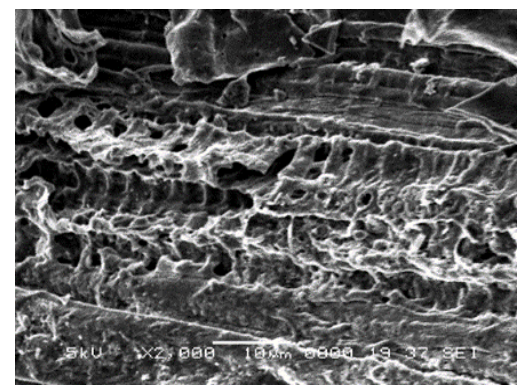

(a)

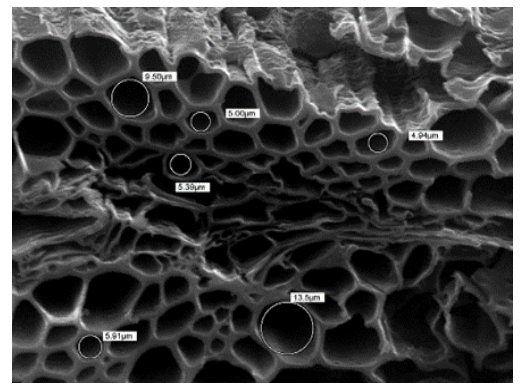

(b)

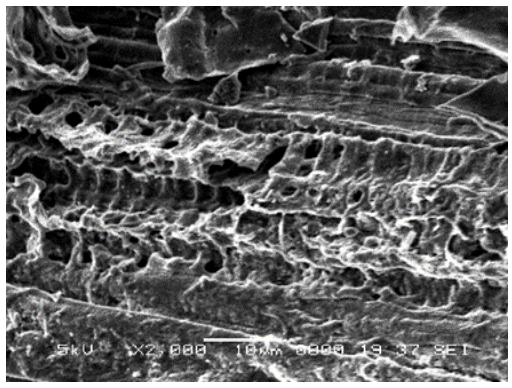

(c)

Fig. 3: SEM images of sugar cane bagasse (SCB): (a) untreated bagasse, (b) activated bagasse, (c) carbon activated bagasse

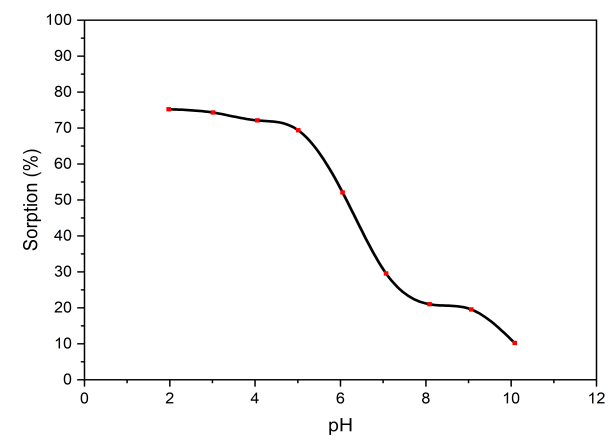

Fig. 4: Effect of $\mathrm{pH}$ on percentage sorption of $\mathrm{Cr}(\mathrm{VI})$

decreases the sorption. At $\mathrm{pH}=2$, maximum sorption was achieved, therefore, further experiments were performed at $\mathrm{pH}=2$. In this study, initially, the percentage sorption was studied at various $\mathrm{pH}$ values $(2-10)$ at unit intervals using activated carbon $0.75 \mathrm{~g} / 100 \mathrm{ml}$. Initial Cr (VI) concentration of $100 \mathrm{mg} / \mathrm{l}$ was shaken for 20 minutes at 150 RPM. It was observed that the sorption of $\mathrm{Cr}$ (VI) increased in acidic conditions at $\mathrm{pH}=5$ to 2 . At $\mathrm{pH}=2$, highest removal $75.21 \%$ was obtained as shown in Figure 4. These results are in agreement with the results of similar investigations carried out earlier [12].

\subsubsection{Impact of Adsorbent Dosage on Sorption Effi- ciency of Activated Carbon}

The impact of the adsorbent dose was investigated for the sorption of $\mathrm{Cr}$ (VI) by changing the adsorbent fraction (0.25-1.25g) using $100 \mathrm{mg} / \mathrm{l} \mathrm{Cr}$ (VI) solution at the optimized condition. It was observed from Figure 5 that the sorption of Cr (VI) increased from $54.9 \%$ to $76 \%$ with an increase of adsorbent dose from 0.25 to $0.75 \mathrm{~g} / 100 \mathrm{ml}$ solution. Further increasing the adsorbent dose shows that the rate of sorption remained constant, which probably caused sorption

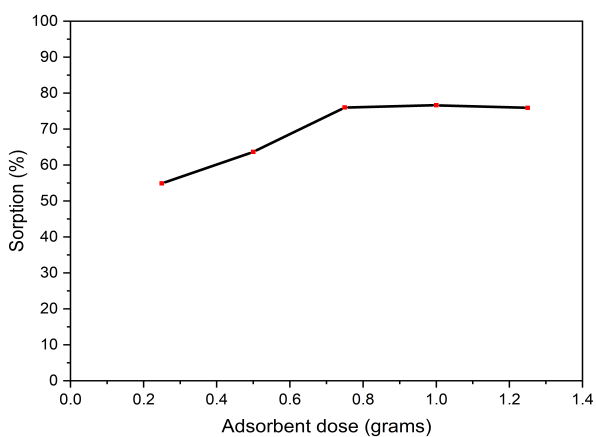

Fig. 5: Impact of adsorbent dosage on percentage sorption of $\mathrm{Cr}(\mathrm{VI})$

sites overlapping provided by the higher dosage of adsorbent [24].

\subsubsection{Effect of Shaking Time on the Sorption Capacity of Activated Carbon}

The effect of shaking time on Cr (VI) sorption was studied by varying the contact time from 5 to 40 minutes with a 5-minute interval. Rotary shaker was used for shaking the sample at $150 \mathrm{rpm}$ with adsorbent dose $0.75 \mathrm{~g} / 100 \mathrm{ml}$. It can be observed in Figure 6 that with an increase in agitation time, the sorption capacity increased until equilibrium was obtained after 20 minutes. The amount of $\mathrm{Cr}$ (VI) adsorbed increased up to $86.66 \%$ within 20 minutes. Hence, for further experiments, the optimum shaking time of 20 minutes was selected. In the present study, the optimum shaking time (equilibrium time of 20 minutes) is less when compared with other adsorbents, i.e., coal: 45 minutes [25][26]; grape waste: 60 minutes [13], rice husk: 120 minutes[9], and Bael fruit: 240 minutes [19]. 


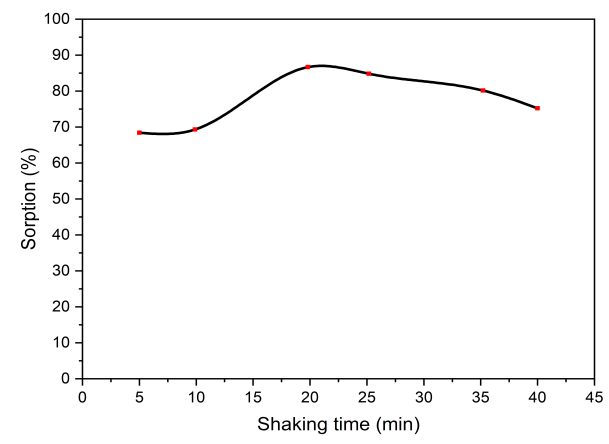

Fig. 6: Effect of shaking time on percentage sorption of $\mathrm{Cr}(\mathrm{VI})$

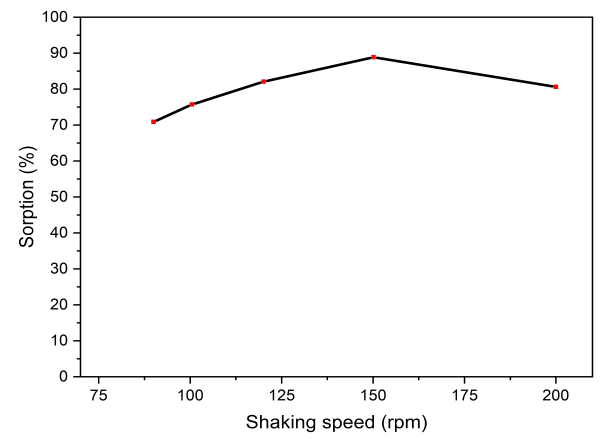

Fig. 7: Effect of shaking speed on percentage sorption of $\mathrm{Cr}(\mathrm{VI})$

\subsubsection{Effect of Shaking Speed on the Sorption Capacity of Activated Carbon}

Experiments were conducted with various shaking speeds (90-200 rpm) at an interval of $20 \mathrm{rpm}$ at optimized conditions as shown in Figure 7. Shaking at an appropriate speed makes the binding site available and provides intimate contact between the adsorbent and adsorbate. Agitation at low speed does not facilitate proper contact of metal ions and active site. Instead, the adsorbent settles at the bottom, rather disperses in the solution. High-speed agitation reduced the metal sorption process. Maximum sorption of $88.88 \%$ was achieved at $150 \mathrm{rpm}$, making all the surface binding sites readily available for $\mathrm{Cr}$ sorption.

\subsubsection{Effect of Sorbate Concentration on the Sorption Capacity of Activated Carbon}

The effect of the initial concentration of $\mathrm{Cr}$ (VI) varying from 60 to $100 \mathrm{mg} / \mathrm{L}$ was examined on the percentage sorption removal with $0.75 \mathrm{~g} / 100 \mathrm{ml}$ of solvent. The sorption percentage increased from $80 \%$ to $98 \%$ as the metal ion concentration decreased,

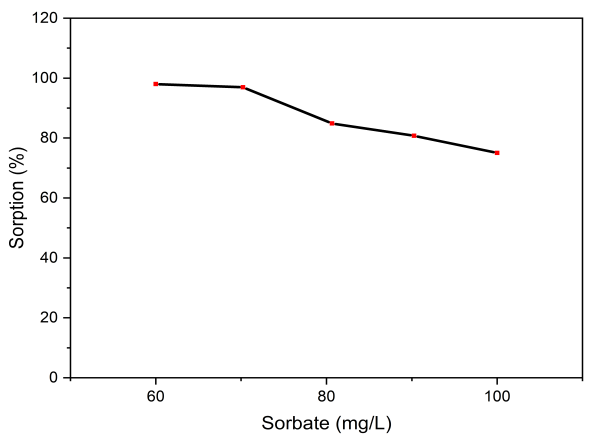

Fig. 8: Effect of sorbate on percentage sorption of $\mathrm{Cr}$ (VI)

as shown in Figure 8. While there is an availability of limited surfaces in case of higher concentrations, hence, it reduces the percentage sorption of Cr (VI). This trend is the same as reported in various literature [2][4][8]. The developed sorbent is found very effective for $\mathrm{Cr}(\mathrm{VI})$ removal from aqueous solution, however, there are not too many studies conducted on $\mathrm{Cr}(\mathrm{VI})$ removal through batch studies. The same efficiency range has been reported by some other studies for arsenic removal from groundwater including [27][28].

\section{Conclusion}

The indigenous adsorbent developed from SCB has shown a substantial potential for $\mathrm{Cr}$ (VI) removal from dilute solutions. The sorption capacity was found impressive. During the parametric study of sorbent, the maximum sorption $98 \%$ of chromium was achieved by optimization of different operational, chemical, and physical parameters. It was observed that sorption is dependent on various parameters such as $\mathrm{pH}$, carbon dose, shaking time, speed, and concentration of the metal ion. Furthermore, the analytical investigations, i.e., FTIR and SEM have endorsed the sorption results as the variations were significant for the before and after samples. These techniques also confirmed the presence of $\mathrm{Cr}$ (VI) ions on the carbon due to the activation process which significantly increased the removal efficiency of the adsorbent. The development sorbent can be applied for industrial and commercial applications for the compliance of local and international set-regulation for effluent treatment standard. Furthermore, this study was a batch scale which can be extended to a continuous or semi-continuous scale with local and regional government support. 


\section{Acknowledgement}

The authors are thankful to the Higher Education Commission, Pakistan and Mehran University of Engineering and Technology, Jamshoro, Sindh-Pakistan for providing financial and technical support to conduct this research work.

\section{References}

[1] D. Mohan and C. U. Pittman, "Activated carbons and low cost adsorbents for remediation of tri- and hexavalent chromium from water," J. Hazard. Mater, vol. 137, no. 2, pp. 762-811, 2006.

[2] M. Costa, "Toxicity and carcinogenicity of $\mathrm{Cr}$ (VI) in animal models and humans," Crit. Rev. Toxicol., vol. 27, no. 5, pp. 431-442, 1997.

[3] K. J. Cronje, K. Chetty, M. Carsky, J. N. Sahu, and B. C. Meikap, "Optimization of chromium(VI) sorption potential using developed activated carbon from sugarcane bagasse with chemical activation by zinc chloride," Desalination, vol. 275, no. 1-3, pp. 276-284, 2011.

[4] P. Miretzky and A. F. Cirelli, "Cr(VI) and $\mathrm{Cr}(\mathrm{III})$ re-moval from aqueous solution by raw and modified lignocel-lulosic materials: A review," J. Hazard. Mater. vol. 180, no. 1-3, pp. 1-19, 2010.

[5] Ş. Parlayici and E. Pehlivan, "Comparative study of Cr(VI) removal by bio-waste adsorbents: equilibrium, kinetics, and thermodynamic," J. Anal. Sci. Technol., vol. 10, no. 1, 2019.

[6] S. O. Owalude and A. C. Tella, "Removal of hexavalent chromium from aqueous solutions by adsorption on modified groundnut hull," Beni-Suef Univ. J. Basic Appl. Sci., vol. 5, no. 4, pp. 377-388, 2016.

[7] P. K. Ghosh, "Hexavalent chromium [Cr(VI)] removal by acid modified waste activated carbons," J. Hazard. Mater, vol. 171, no. 1-3, pp. 116-122, 2009.

[8] Sirajuddin, L. Kakakhel, G. Lutfullah, M. I. Bhanger, A. Shah, and A. Niaz, "Electrolytic recovery of chromium salts from tannery wastewater," J. Hazard. Mater., vol. 148, no. 3, pp. 560-565, 2007.

[9] M. Bansal, U. Garg, D. Singh, and V. K. Garg, "Removal of $\mathrm{Cr}$ (VI) from aqueous solutions using pre-consumer processing agricultural waste: A case study of rice husk," J. Hazard. Mater, vol. 162, no. 1, pp. 312-320, 2009.

[10] M. Pazos, M. Branco, I. C. Neves, M. A. Sanromán, and T. Tavares, "Removal of $\mathrm{Cr}(\mathrm{VI})$ from aqueous solutions by a bacterial biofilm supported on zeolite: Optimisation of the operational conditions and scale-up of the bioreactor," Chem. Eng. Technol., vol. 33, no. 12, pp. 2008-2014, 2010.

[11] E. Pehlivan and T. Altun, "Biosorption of chromium(VI) ion from aqueous solutions using walnut, hazelnut and al-mond shell," J. Hazard. Mater, vol. 155, no. 1-2, pp. 378-384, 2008..

[12] A. B. Albadarin, A. H. Al-Muhtaseb, N. A. Al-laqtah, G. M. Walker, S. J. Allen, and M. N. M. Ahmad, "Biosorption of toxic chromium from aqueous phase by lignin: Mechanism, effect of other metal ions and salts," Chem. Eng. J., vol. 169, no. 1-3, pp. 20-30, 2011.

[13] R. Chand, K. Narimura, H. Kawakita, K. Ohto, T. Watari, and K. Inoue, "Grape waste as a biosorbent for remov-ing Cr(VI) from aqueous solution," J. Hazard. Mater, vol. 163, no. 1, pp. 245-250, 2009.

[14] S. E. A. Sharaf El-Deen and G. E. Sharaf El-Deen, "Adsorption of $\mathrm{Cr}(\mathrm{VI})$ from Aqueous Solution by Activated Car-bon Prepared from Agricultural Solid Waste," Sep. Sci. Technol., vol. 50, no. 10, pp. 1469-1479, 2015.
[15] E. Gomes, R. Kumar Gupta, P. Kumar Sinha, A. Professor, and C. Engineering Depart ment, "Adsorption Studies on Removal of Chromium from Synthetic Waste Water using Activated Carbon prepared from Rice Husk and Sugarcane Bagasse," Int. J. Eng. Dev. Res., vol. 5, no. 2, p. 1856, 2017.

[16] B. Singha, T. K. Naiya, A. kumar Bhattacharya, and S. K. Das, "Cr(VI) Ions Removal from Aqueous Solutions Using Natural Adsorbents - FTIR Studies," J. Environ. Prot. (Irvine,. Calif)., vol. 02, no. 06, pp. 729-735, 2011, doi: 10.4236/jep.2011.26084.

[17] M. K. Rai et al., "Removal of hexavalent chromium Cr (VI) using activated carbon prepared from mango kernel activated with H3PO4," Resour. Technol., vol. 2, pp. S63-S70, 2016.

[18] I. Bhatti, K. Qureshi, R. A. Kazi, and A. K. Ansari, "Preparation and Characterisation of Chemically Activated Almond Shells by Optimization of Adsorption Parameters for Removal of Chromium VI from Aqueous Solutions," Engineering, no. Vi, pp. 199-204, 2007.

[19] J. Anandkumar and B. Mandal, "Removal of Cr(VI) from aqueous solution using Bael fruit (Aegle marmelos cor-rea) shell as an adsorbent," J. Hazard. Mater, vol. 168, no. 2-3, pp. 633-640, 2009.

[20] T. Khan et al., "Cr(VI) adsorption from aqueous solution by an agricultural waste based carbon," RSC Adv., vol. 6, no. 61, pp. 56365-56374, 2016.

[21] K. Qureshi, R. A. Kazi, and A. K. Ansari, "Preparation of activated carbon from Rice Husk and Optimization of Adsorption Parameters for the removal of Cr (VI) from aqueous solution," Mehran Univ. Res. J. Eng. Technol., vol. 26, no. 3, pp. 261-266., 2007.

[22] E. W. Washburn, "Proceedings of the National Academy of Sciences," Proc. Natl. Acad. Sci., vol. 7, no. 4, pp. 115-116., 1921.

[23] E. Malkoc, Y. Nuhoglu, and Y. Abali, "Cr (VI) adsorption by waste acorn of Quercus ithaburensis in fixed beds: Prediction of breakthrough curves," Chem. Eng. J., vol. 119, no. 1 , pp. $61-68,2006$.

[24] C. Namasivayam, D. Prabha, and M. Kumutha, "Removal of direct red and acid brilliant blue by adsorption on to banana pith," Bioresour. Technol., vol. 64, no. 1, pp. 77-79, 1998.

[25] J. Anwar, U. Shafique, M. Salman, Waheed-uz-Zaman, S. Anwar, and J. M. Anzano, "Removal of chromium (III) by using coal as adsorbent," J. Hazard. Mater, vol. 171, no. 1-3, pp. 797-801, 2009.

[26] J. Anwar, U. Shafique, Waheed-uz-Zaman, M. Salman, A. Dar, and $\mathrm{S}$. Anwar, "Removal of $\mathrm{Pb}(\mathrm{II})$ and $\mathrm{Cd}(\mathrm{II})$ from water by adsorption on peels of banana," Bioresour. Technol., vol. 101, no. 6, pp. 1752-1755, 2010.

[27] Z. A. Solangi, K. H. Mangi, I. Nazir, K. Qureshi, and M. Areeb, "Development and Characterization of Iron Coated Chitosan Beads (ICCB) to remove Arsenic from Groundwater," J. Appl. Emerg. Sci., vol. 10, no. 2, p. pp-155, 2020.

[28] K. Qureshi, Y. H. Mangi, F. H. Mangi, K. H. Mangi, and S. R. Samo, "Surface adsorption study of saponified orange waste gel for arsenic (III) removal," Eng. Sci. Technol., vol. 13, no. 2 , pp. $54-58,2014$. 